\title{
Lean layout design: a case study applied to the textile industry
}

\author{
Ana Paula Lista $^{\mathrm{a} *}$ (D), Guilherme Luz Tortorella ${ }^{\mathrm{a}, \mathrm{b}, \mathrm{c}}$ (D), Marina Bouzon ${ }^{\mathrm{a}}$ (D), Sherif Mostafa ${ }^{\mathrm{d}}$ (D), \\ David Romero ${ }^{\mathrm{e}}$ \\ aUniversidade Federal de Santa Catarina, Florianópolis, SC, Brasil \\ ${ }^{\text {b}}$ The University of Melbourne, Melbourne, Australia \\ IAE Business School, Universidad Austral, Buenos Aires, Argentina \\ ${ }^{\mathrm{d}}$ Griffith University, Brisbane, Australia \\ eInstituto Tecnológico y de Estudios Superiores de Monterrey, Mexico City, Mexico \\ *anapaulalista@gmail.com
}

\begin{abstract}
Paper aims:This research proposes a new facility layout for an Indian textile company based on guidelines for Systematic Layout Planning (SLP) and Lean Manufacturing (LM).

Originality: This paper provides an original industrial case study with valuable insights for practitioners interested in layout redesign. The obtained results encourage assuming its transferability to similar situations than textile industry.

Research method: To showcase the application of LM on plant layout design, an ABC Industries' facility is selected. Information is collected through multiple site visits and semi-structured interviews with the company's key staff, as well as examination of relevant company documentations.
\end{abstract}

Main findings: Some of the expected results include costs reduction handling, organic growth elimination, unnecessary movements reduction and less arrangement adjustments.

Implications for theory and practice: This paper provides an original industrial case study with valuable insights for the adaptation of the SLP model to reformulate plant designs.

Keywords:

Lean manufacturing. Plant layout design. Systematic layout planning.

How to cite this article: Lista, A. P., Tortorella, G. L., Bouzon, M., Mostafa, S., \& Romero, D. (2021). Lean layout design: a case study applied to the textile industry. Production, 31, e20210090. https://doi.org/10.1590/0103-6513.20210090

Received: July 26, 2021; Accepted: Oct. 25, 2021.

\section{Introduction}

Among the strategies to reach customers' expectations and to increase competitiveness in the modern market, Lean Manufacturing (LM) stands out as it provides greater flexibility, quality, and responsiveness to a production system (Bai et al., 2019). LM has proven to be an effective operations management strategy, which helps companies to adapt their value chain to market demand through continuous improvement (Henao et al., 2019). One of the main applications of LM concerns "plant layout optimization". Regardless of the company's size, its "layout design" is decisive for achieving greater efficiency in materials handling and, consequently, for reducing manufacturing costs (i.e., material handling costs). Therefore, applying $\mathrm{LM}$ principles in plant layout designs is a key strategy for surviving in competitive markets (Zhang et al., 2019; Kovács, 2020).

Determining the layout of a manufacturing system might be challenging since the most efficient shop floor arrangement depends on unequal requirements of different natures and departments within a facility (Liu \& Liu, 2019). Moreover, this decision can be affected by several factors such as the kind and the complexity of 
the product to be made, the quality of the raw materials, the complexity of the manufacturing process, the available shop floor area, and the arrangement of departments constituting the production process among other decisions (De Carlo et al., 2013; Flessas et al., 2015).

In the past, plant layout modifications were triggered after there was a need for change, and companies grew in a disorderly and disorganized way. For example, every time a newly purchased equipment was acquired, the existing production facility layout had to be rearranged to accommodate that equipment. Most of the time, departments were arranged according to space availability or in the most convenient way (Shewale et al., 2012; Henao et al., 2019). Over time, the layout's planning received more attention, especially after researchers acknowledged the layout contribution to improving production management performance. Then, it became important to know how companies were affected by different variations in their physical assets configurations (Klausnitzer \& Lasch, 2019).

Since the beginning of industrialization, companies have attempted to create efficient layouts design, and many methods have been utilized by manufacturing engineers to come up with the most efficient facility arrangement. The first Systematic Layout Planning (SLP) was developed by Richard Muther in 1973. Muther's idea was to develop a procedural method to identify, evaluate and visualize areas, equipment and machines involved in planning the physical arrangement (Muther, 1973). Since then, several studies have applied Muther's SLP for layout designs. Yang et al. (2000) applied it for designing a semiconductor facility; Watanapa \& Wiyaratn (2012) employed it in a pulley facility; Shewale et al. (2012) utilized it in a compressor facility; and Santos et al. (2014) applied it for an automotive battery layout.

Although SLP has been popular in the literature, it cannot be repetitively applied to all contexts because each layout facility has its characteristics and limitations (Matt, 2014; Tomelin \& Colmenero, 2010). For this reason, some authors have also advanced the SLP method (Lin et al., 2015). In Inglay \& Dhalla (2010), an SLP method is developed to design and optimize facility layouts for supermarket planning. Regarding the studies of layout design in the textile industry, Brahmadeep \& Thomassey (2014) investigated the production flow and the distribution logic of bobbins for the rewinding process in a yarn dyeing factory. Yet, literature reports on multiple models for implementing SLP (Rawabdeh \& Tahboub, 2006; Decker Junior et al., 2019).

This research aims to illustrate the use of LM and SLP as a simplified approach for a plant layout design for an Indian textile company. All stages of layout development are described and the economic benefits of the final solution are also estimated. The paper is structured as follows: Section 2 reviews the scientific literature and gives a brief overview of factors considered during a facility layout design. Section 3 explains the research methodology and simplifies the criteria of layout alternative selection. In Section 4, an example of a facility is presented to apply the simplified SLP approach in a real industrial case of a textile manufacturing facility. Section 5 provides discussion on the results. Finally, Section 6 concludes with the main research findings and provides future research directions.

\section{Literature review}

According to Dongre \& Mohite (2015), a company's productivity might be highly affected by its facility layout. It is estimated that material flow cost contributes from 30 to $70 \%$ of the total manufacturing cost of a product (Naqvi et al., 2016). Thus, it becomes critical that facilities' arrangement is organized effectively through a systematic methodology, also known as SLP. Among the strategies for SLP, Lean Manufacturing (LM) stands out as a successful alternative to design facility plants, especially for improving productivity, operation control and material handling (Pattanaik \& Sharma, 2009; De Carlo et al., 2013). Gnanavel et al. (2015) state that a good LM layout design minimizes the distance travelled by personnel (i.e., motion) and material flows (i.e., transport). On the other hand, Hicks et al. (2015) argue that a typical LM facility model includes one unit at a time production, non-value-added time removed, relocation of required resources to the point of usage, and all processes balanced to produce at Takt time (Marodin et al., 2015; Fogliatto et al., 2019).

Layout planning and development might be considered time-consuming and a difficult task (Matt, 2014). However, some techniques are generally used to plan layout designs like Value Stream Mapping (VSM), product family identification, activity relationship chart, and block diagram (Djassemi, 2007; Naqvi et al., 2016; Tortorella et al., 2017). According to Rother \& Shook (2003) and Jones et al. (2011), VSM can be understood as a visual representation of all value and non-value-added activities to manufacture a product with its materials and information flows. Through the current value flow map, it is possible to follow a product's production path as they occur, from supplier to customer, and then generate another flow chart to illustrate a possible future situation with greater performance (Luz et al., 2020). 
Another technique to design layouts is product family identification. Rother \& Shook (2003) define it as a tool to gather a group of products with similar processing steps and work contents. To identify and distinguish product families, LM practitioners use a product family analysis matrix, in which all products are positioned down the left side of a spreadsheet and all the processes across the top (Tortorella et al., 2018). Then, products and equipment existing in each process are identified. If a product should go into specific equipment, the corresponding matrix cell receives an " $X$ " and, if there is an alternative, the letter " $A$ " is assigned to identify it.

In addition, a qualitative method widely used for designing layouts is the activity relationship chart (Durmusoglu, 2018). Slack et al. (2010) describe it as being an indicator of the degree of distance between pairs of activities. The activity relationship diagram is also called the affinity analysis diagram, and it shows the relationship of every department, office, or service area with every other department. It helps to organize activities that need to be close to each other in the relevance of importance by displaying the closeness rating between them. This rating is based on an "A, E, I, O, U, and X" closeness level (A: absolutely necessary; E: especially important; 1 : important; 0: ordinary; U: unimportant; $X$ : prohibited or undesirable).

Activity relationship charts provide relevant information to design a first layout attempt, known as a block diagram (Slack et al., 2010). Block diagram indicates broad areas of space within the given building dimensions for occupancy by various departments. The shapes or blocks obtained may be somewhat irregular, thus requiring manual adjustment to regulate the physical size of the department and the physical constraints of the building. Even though this first layout is dimensionless, it helps to create master layout proposals by providing basic information of design requirements (Durmusoglu, 2018).

Developing an SLP for a manufacturing facility requires a combination of experience and theory. Traditionally, there are two approaches for the SLP problem. The first one is a quantitative approach based on a distance function aiming at minimizing the total material handling cost between departments. The second one is a qualitative approach based on a closeness function aiming at maximizing closeness rating scores between departments (Zhenyuan et al., 2011). In the literature, some authors propose ways of designing facility layouts, with more specific applications like Inglay \& Dhalla (2010), in which an SLP method was developed to design and optimize facility layouts for supermarket planning, or Lin et al. (2015), for applications in the healthcare sector. Meanwhile, other SLPs have a broader application, reaching all building constructions like Kim et al. (2012). More recently, Naqvi et al. (2016) provide a comprehensive comparison of different approaches used in SLP. Despite the several possibilities for layout design in literature, the challenge is determining the best alternative for operational performance (De Carlo et al., 2013).

Regarding the studies of layout design in the textile industry, some research works can be found. For example, Brahmadeep \& Thomassey (2014) investigated the production flow and the distribution logic of bobbins for the rewinding process in a yarn dyeing factory, comparing different scenarios of production (manual and automatic) using computer simulation tools. More recently, Santos et al. (2019) developed a U-type layout of wool-based garments wholesale and retail by using SLP. Further, Ruiz et al. (2019) detail the steps that SMEs can follow in the search for a plant distribution model under the SLP tool. Although layouts have been designed by manufacturing and industrial engineers for decades, there is still less documented evidence of their implementation in textile industries, especially considering guidelines for layout redesign associates with the lean concept (Rawabdeh \& Tahboub, 2006; Dongre \& Mohite, 2015).

Additionally, literature reports on multiple models for implementing SLP (Rawabdeh \& Tahboub, 2006; Decker Junior et al., 2019). One interesting approach of SLP is proposed by Tortorella \& Fogliatto (2008) and is composed of three phases: $(i)$ analyze, (ii) research and (iii) selection. Phase 1 - begins with evaluating the material flow by applying a from-to diagram and an activity relationship chart to represent the flow intensity between different departments. Then, it proceeds with the comparison analysis between the available physical area and the required area. Phase 2 - concerns the research stage, in which the relationship chart is complemented with departments areas forming a block correlation diagram. Through this step, the relevant information is acknowledged to give insights on creating the first layout proposals. Finally, after developing the layout proposals, the selection phase begins (Phase 3). During that, layouts proposals undergo a feasibility assessment and approval to consider if the design criteria have been satisfied.

\section{Research methodology}

To explore the viability of the proposed approach for layout facility, a real world case study in the textile industry is presented in this section. The chosen company is a medium-size Indian producer, known as $A B C$ Industries, to illustrate the developed SLP methodology for implementing LM concepts on the shop floor. $A B C$ Industries is an Industrial Bulk Packaging Solution provider located in the north of India. The company is 
equipped with the latest technologies to meet the market's need regarding Flexible Intermediate Bulk Containers (FIBC), also known as "Big Bags". Their products are used for industrial and bulk transportation of goods (e.g., cement, food grains, chemicals, fertilizers, pharmaceuticals, and other materials). During the last ten years of steady growth, production management had paid more attention to timely order fulfillment and neglected the necessary organizational and structural improvements in manufacturing. The organization was not prepared for this rapid growth and the rising market pressure led to productivity losses and serious quality problems. Instead of treating the problem as its root by changing processes organization and its structure, more often partial orders were outsourced to third parties that in turn led to a decline in profitability. Production management, therefore, decided to create an optimized plant layout design for $A B C$ Industries.

To create an optimized plant layout design for ABC Industries, this study adopted the SLP model proposed by Tortorella \& Fogliatto (2008). The LM and SLP application in the layout design for the ABC manufacturing facility consists of nine sequential stages as shown in Figure 1.

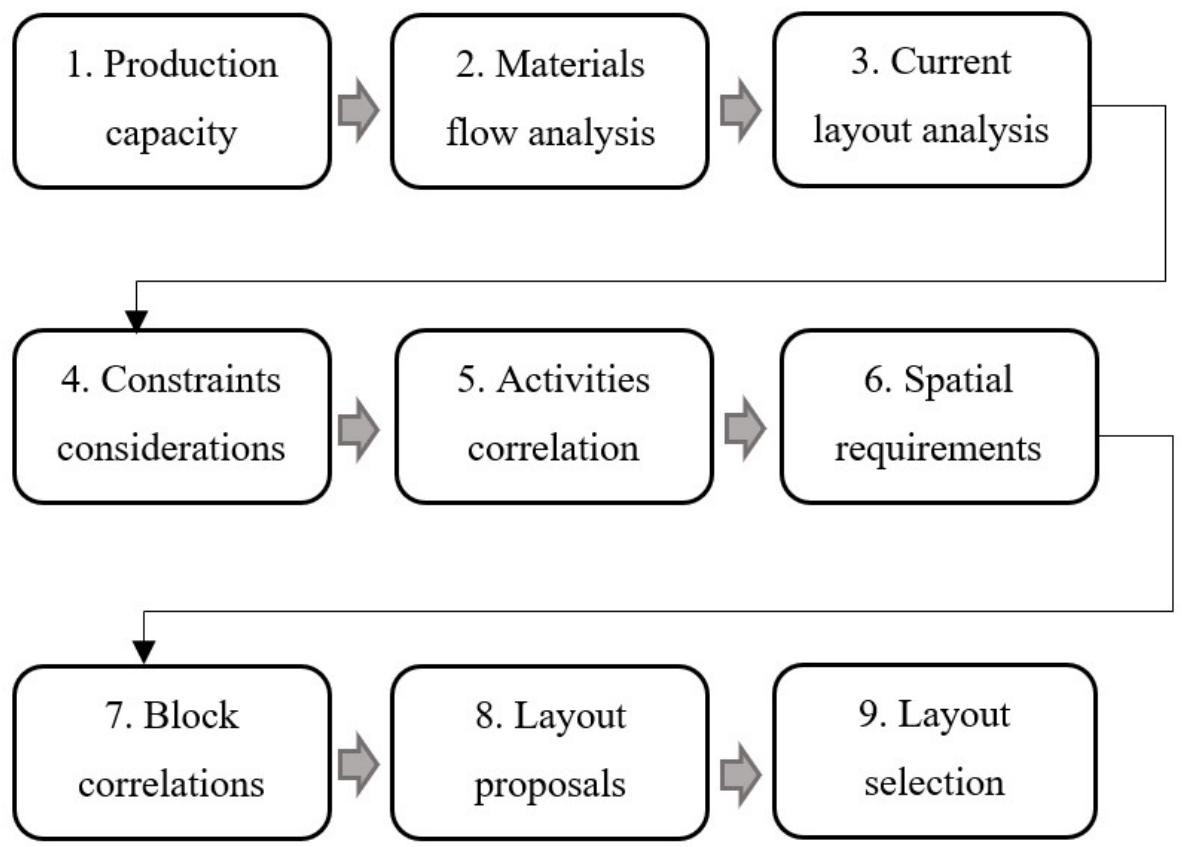

Figure 1. Developed SLP Model.

The first three stages of the SLP model refer to the study of the current situation of the company. More specifically, Stage 1 identified product families and evaluate the machine's capacity for the overall production activities. Stage 2 described the current flow of materials through a flow chart representation (i.e., a VSM). Stage 3 began with several factory visits to identify the current plant layout design and resource's allocations. For that, data collection occurred through multiple site visits in $A B C$ Industries and semi-structured interviews with the company's key staff, as well as examination of relevant company documentations (i.e., layout planning from other facilities of the company, expansion planning, among others) throughout an 15-months period (from October 2016 to December 2017).

The following three stages concern the identification of plant layout requirements and opportunities for improvements to guide further proposal's development. Stage 4 aimed to determine premises and restrictions regarding the plant layout design. During this stage, several interviews and meetings' sessions with experts from Industry $\mathrm{ABC}$ were required to understand the main premises regarding the facility layout. In Stage 5 an activity relationship chart was created to help to find requisites considering the proximity level between departments. Stage 6 refers to the determination of space requirements so that every machine and storage area can be considered before planning layout proposals. After completing Stage 5 and 6, another validation meeting was scheduled with the managers from $A B C$ industry. 
When completing the previous stages, it was possible to proceed with developing the final layout, firstly by creating a block correlation diagram (Stage 7), and then by proposing macro- and micro-layouts (Stage 8). Lastly, the final proposal was selected according to the company's criteria (Stage 9). During these final stages, further visits to the factory were necessary in order to validate the layouts and become familiar with the cultural, economic and social context of the region. Some additional telephone calls and virtual meetings were also required for the ultimate adjustments.

\section{Results}

\subsection{Stage 1: Production capacity}

Firstly, $A B C$ Industries products are grouped according to a product family classification. In this way, the flow of operations within the manufacturing system becomes more visible and easier to understand, facilitating the identification of points for improvement. In this analysis, six product families are found, as shown in Table 1.

After completing the product-family classification, Big Bags demand level and the capacity of product families are investigated for two purposes: ( $i$ ) to check if the company's current capacity can meet Big Bags' demand, and (ii) to measure the amount of demand's surplus for creating a plant layout design flexible enough for future expansions.

Table 1. Product-Family Classification.

\begin{tabular}{cc}
\hline Family ldentification & Family Composition \\
\hline 1 & Circular Fabric \\
2 & Flat Fabric \\
3 & Webbing Mono Extrusion \\
4 & Raffia, MFY and Tie Cord \\
5 & MFY and Filler Cord \\
6 & MFY \\
\hline
\end{tabular}

MFY: Multifilament yarn

\subsection{Stage 2: Material flow analysis}

For the material flow analysis, data were collected regarding vehicles, material movement, and equipment's features. Demand and capacity levels, number of machines, occupied area, production time, and inventory levels are provided with the help of workers, supervisors, engineers, and executives. In this way, the current VSM is created to identify the intensity of the material flow for each product family. Hence, the current VSM does not display one single value stream but the superposition of six value streams. Afterwards, the family with the greatest contribution to the materials flow is identified: the one coming from the circular loom. Figure 2 is an illustration of the current macro VSM, which covers all product families.

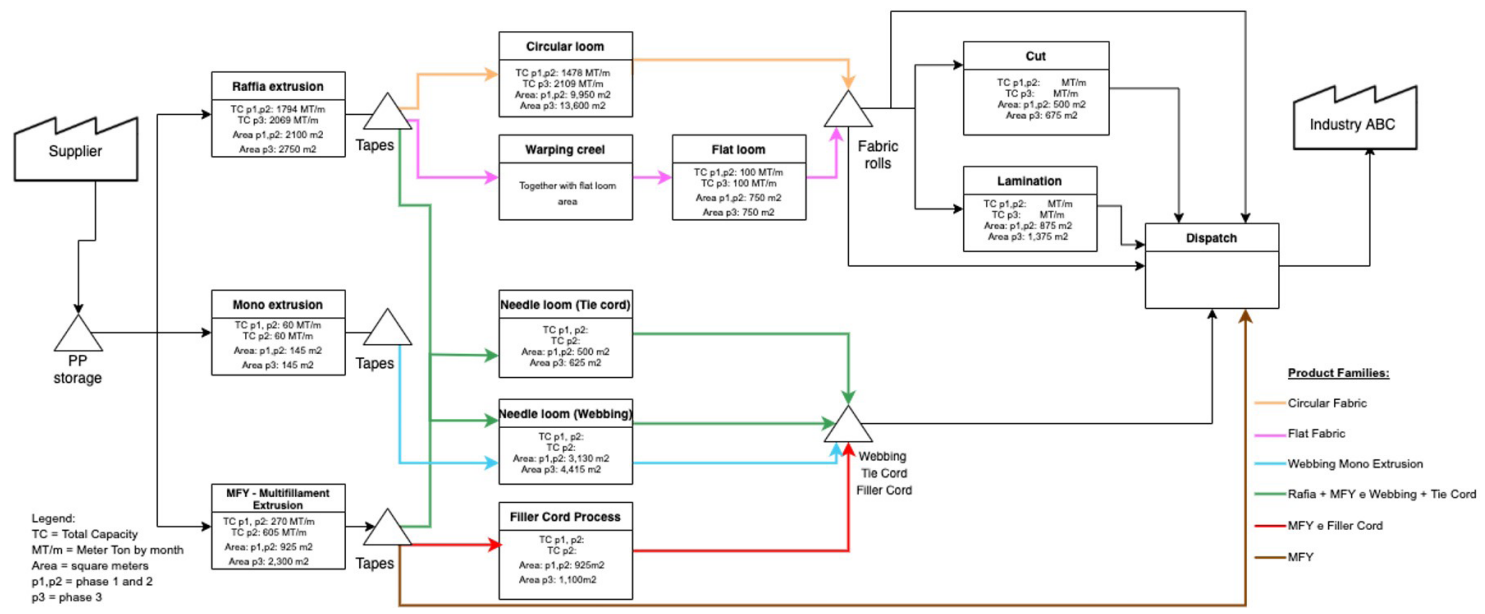

Figure 2. Current VSM of All Product Families. 


\subsection{Stage 3: Current layout analysis}

To identify the current plant layout design, three visits lasting 1-2 weeks to the facility where required. After completing that, it was possible to verify some issues concerning the way $\mathrm{ABC}$ Industries arrange equipment and other resources over the available shop floor area. The company's current layout consists of a set of production units separated from each other. In the current arrangement, the distribution of resources does not follow a specific pattern. Instead, they are randomly distributed, depending on the space available for allocation. This information brings insights that the final plant layout project should eliminate the uncontrolled growth of the observed scenario by creating a proposal according to the flow of materials (and information). Figure 3 shows the current plant layout arrangement and the same layout complemented with a spaghetti diagram to visualize the distribution of material flows. At the end of Stage 3, it was possible to verify some deficiencies in the current plant layout design, such as material handling waste; transportation waste; functional layout with production areas isolated from each other; and expansion plans not considered in the flow of materials.
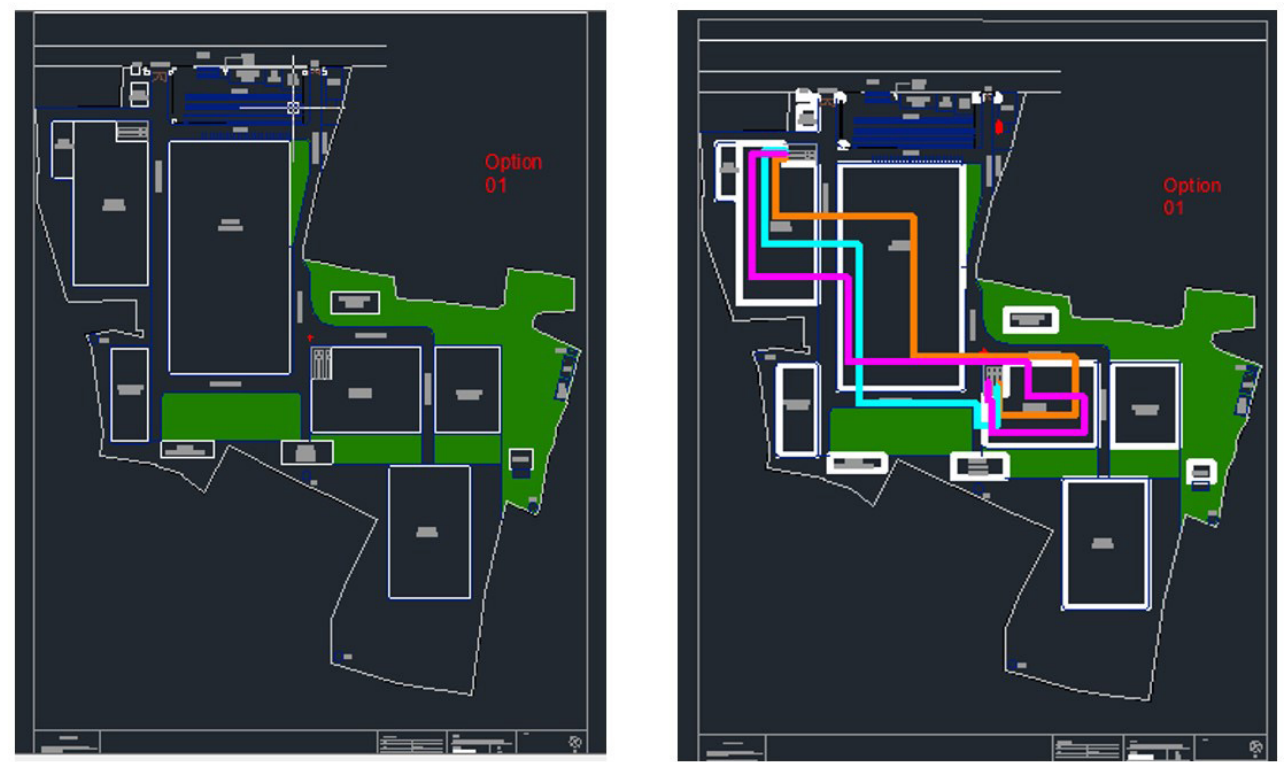

Figure 3. Current Plant Layout and Spaghetti Diagram. Note: The orange line represents the circular loom flow, the green line represents the needle loom flow, and the pink line represents the flat loom flow.

\subsection{Stage 4: Constraints considerations}

After visiting the facility, it was possible to conduct semi-structured interviews with the production managers. Six interviews were applied to collect data and to get familiar with the Indian culture. According to the "Vastu" belief from Indian culture, the site shape affects the well-being of the inmates. Some shapes have a good effect, while others have a bad effect and some others can be used after making corrections by building a "Vastu" compound wall in a suitable shape. In addition, the shape of a site plays an important role in the overall energy balance of any plot. Hence, the shaping and the plots' balance were taken into consideration before creating layouts proposals. All constraints regarding the facility design are pointed below:

- The project must include all warehouses in the same physical space;

- The tallest building must be positioned in the southeast region of the facility;

- The facility must have two openings, one of which is only for evacuation purposes;

- Sheds must be rectangular (religious constraint);

- For each rectangular warehouse, the diagonals' meet point must remain empty (also known as Brahmstal pointreligious constraint). 


\subsection{Stage 5: Activities correlation}

The activity relationship chart offers an overview of the closeness correlation along with practical constraints for each pair of activities. In addition, it gives relevant information on the priorities relationships for layout propositions. The relation in Figure 4 shows that those pairs of activities marked with the letter 'A' should be positioned as close as possible. For example, the raw materials for the extrusion process (i.e., polyproline) and raffia extrusion are identified at that relationship level.

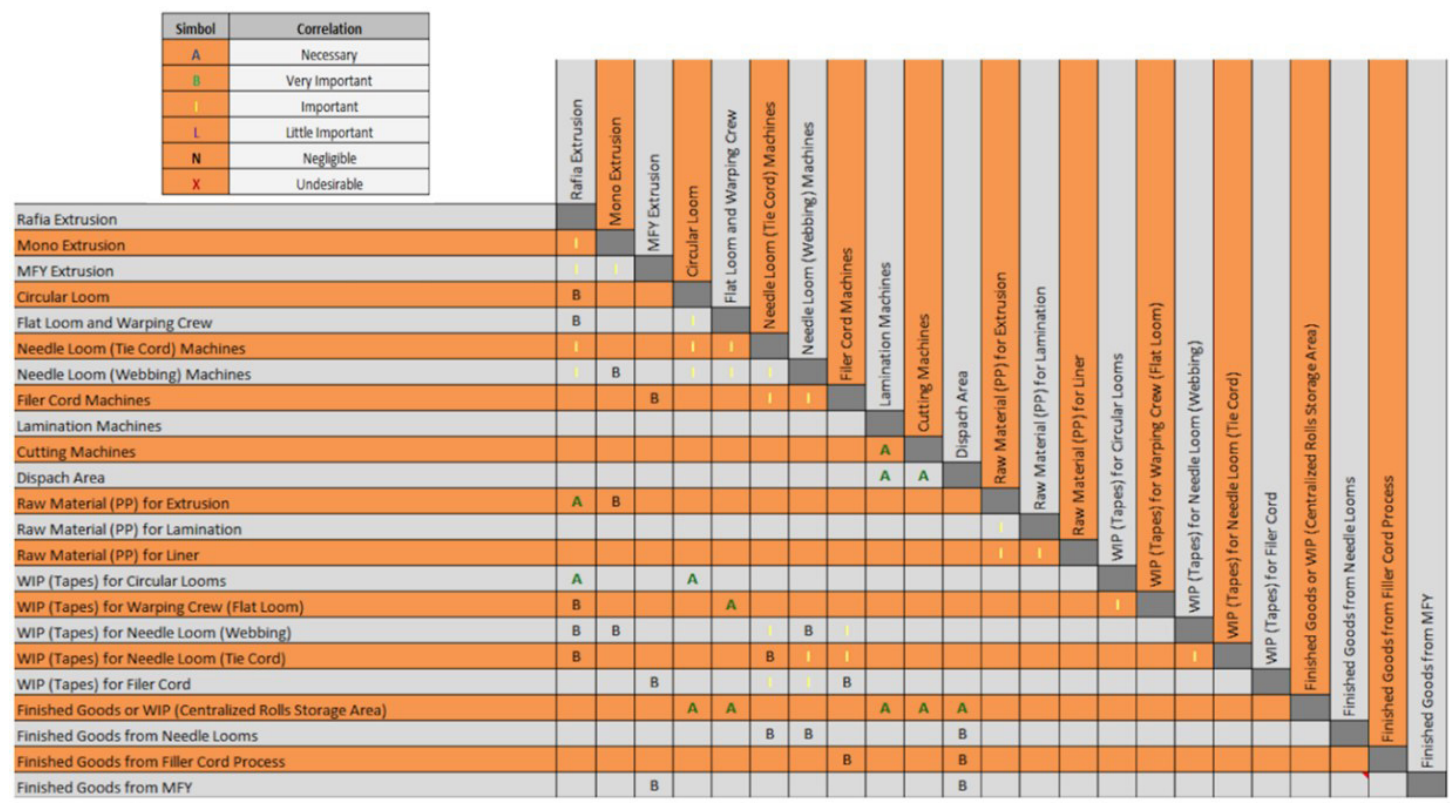

Figure 4. Activity Relationship Chart.

\subsection{Stage 6: Spatial requirements}

Stage 6 refers to the amount of floor space assigned to each piece of equipment. This decision is critical to design the new layout since shop floor space might be expensive and play a vital role in future expansion. Hence, some equipment's characteristics were taken into account for calculating the space required to allocate them at the new plant layout design (e.g., quantity, type, and dimensions). After estimating the dimensions of each area, the relationship between area blocks was designed via AutoCad ${ }^{\circledR}$ software. In addition, the stock size was also estimated based on some calculations provided by $A B C$ Industries. Figure 5 illustrates the estimated areas for a few types of equipment.

\subsection{Stage 7: Block correlations}

Stage 7 converted the activity relationship chart into a block diagram area (see Figure 6), considering the space requirements calculated previously (see Figure 5). When designing the block diagram, the appropriate area for each operation was assigned and drawn according to the current production capacity.

\subsection{Stage 8: Layout proposals}

After analyzing the gaps from the current state plant layout, some changes in the flow of materials were proposed for the new design. Hence, five possibilities were tested to verify the best flow of material concept: 


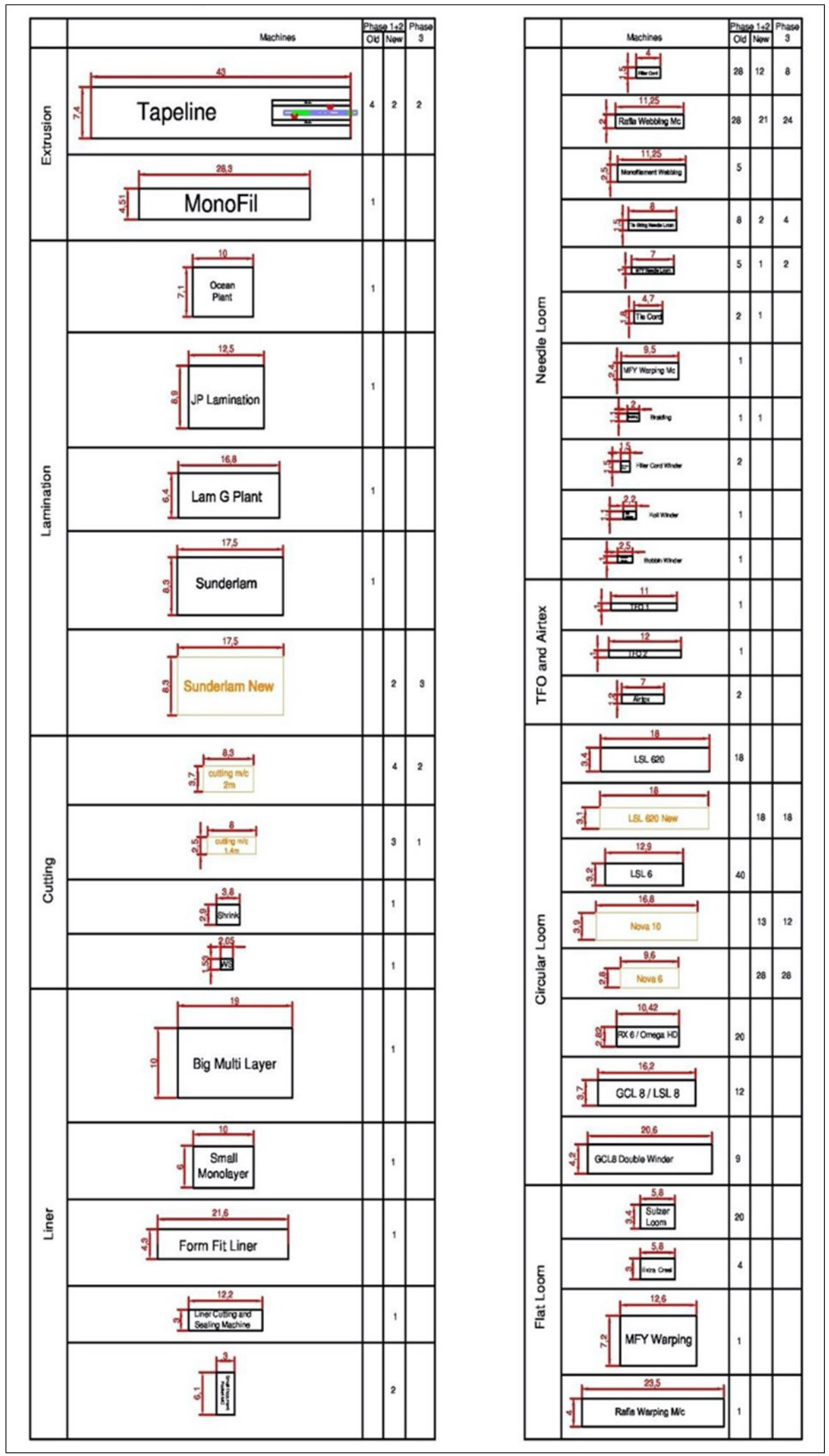

Figure 5. Spatial Requirements. 


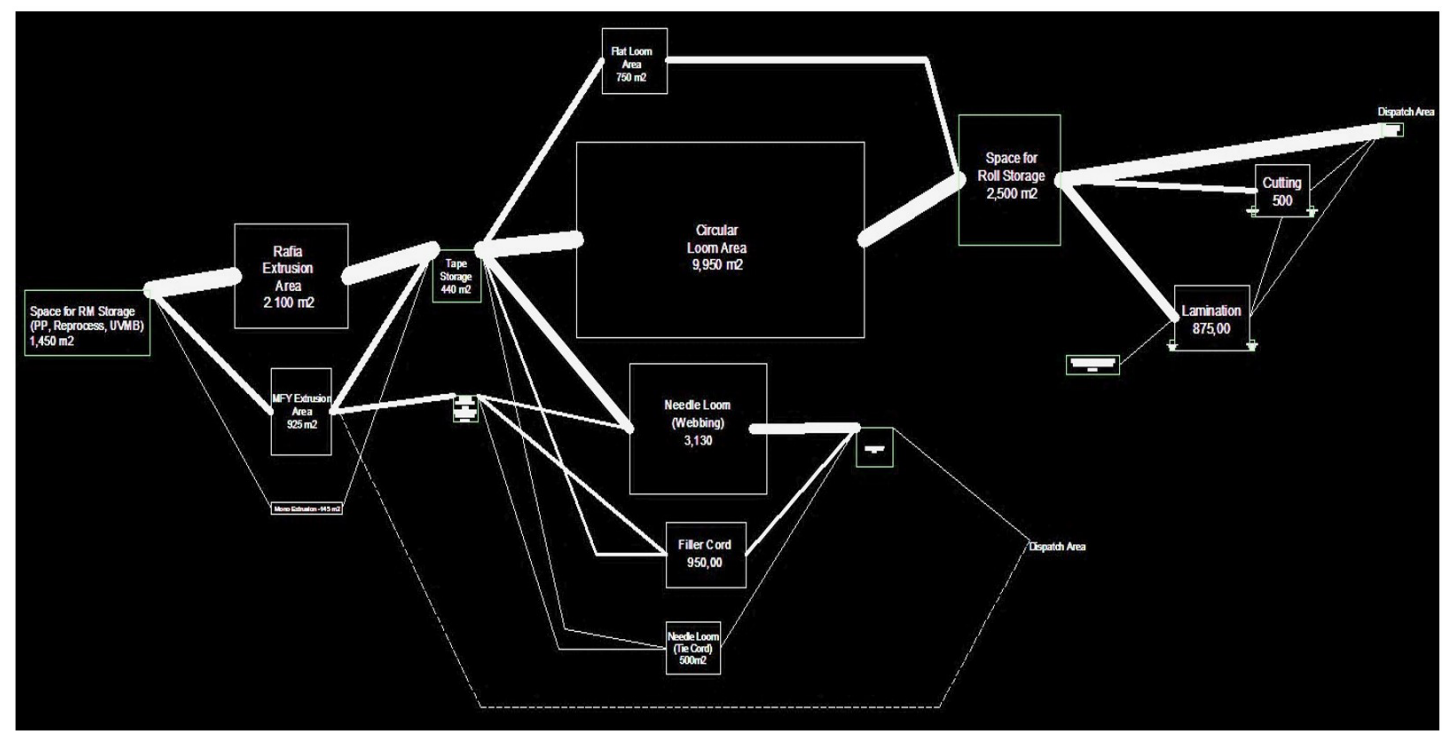

Figure 6. Block Diagram Area.

- Concept A: U-shaped flow (starts and ends at the top of the facility design);

- Concept B: Linear top-down and U-shaped flow (linear - starts at the top and ends at the bottom; U-shaped starts and ends at the top);

- Concept C: Linear top-down flow (starts at the top and ends at the bottom);

- Concept D: Linear down-top flow (starts at the bottom and ends at the top); and

- Concept E: Linear down-top and U-shaped flow (linear - starts at the bottom and ends at the top; U-shaped starts and ends at the bottom).

The best alternative of each concept was investigated to create an optimized solution. Finally, the chosen concepts are ' $A$ ' generate the finest solution. Usually, U-shaped material flow is used to optimize the space used with greater control over production processes and 'B', direct communication with previous and subsequent activities to the area under study while 'B' a linear flow provides a simple path for materials transportation (Santos et al., 2019). Through the simulations in software, it was possible to identify that while concept B has a good flow of material, 'A' concept A has an interesting approach regarding the shed's shapes and the expansion areas (i.e., square-shaped, and modular). Therefore, the finest solution was a mix of both, considering the shapes of concept ' $A$ ' and the material flow of 'B'. Subsequently, the macro layout proposals were designed based on this mixed concept, resulting in innumerous possibilities. The one that best fits this project's aim was denominated macro proposal B-10, which is represented in Figure 7.

\subsection{Stage 9: Layout selection}

Subsequently, the macro layout proposal was sent to $A B C$ Industries for evaluation. Due to an Indian religious belief known as "Vastu", the layout arrangement designed was adapted to meet the requirements of the local culture. This way, another proposal was created with exclusively rectangular sheds. After a few modifications, the final macro proposal which corresponds to the company's expectations was proposal B-11 (see Figure 8).

When the final macro proposal was chosen, the following step was creating individual micro layout proposals for all machinery groups based on the materials flow. Each micro proposal was evaluated considering its positive and negative aspects. After analyzing all individual micro layout proposals regarding machinery groups, a second evaluation was carried out to determine the correlation and compatibility. Then, a new design was created to allocate all micro designs into a single proposal, gathering the best part of each proposal to optimize the flow of materials and transportation. Figure 9 illustrates the final micro layout. 


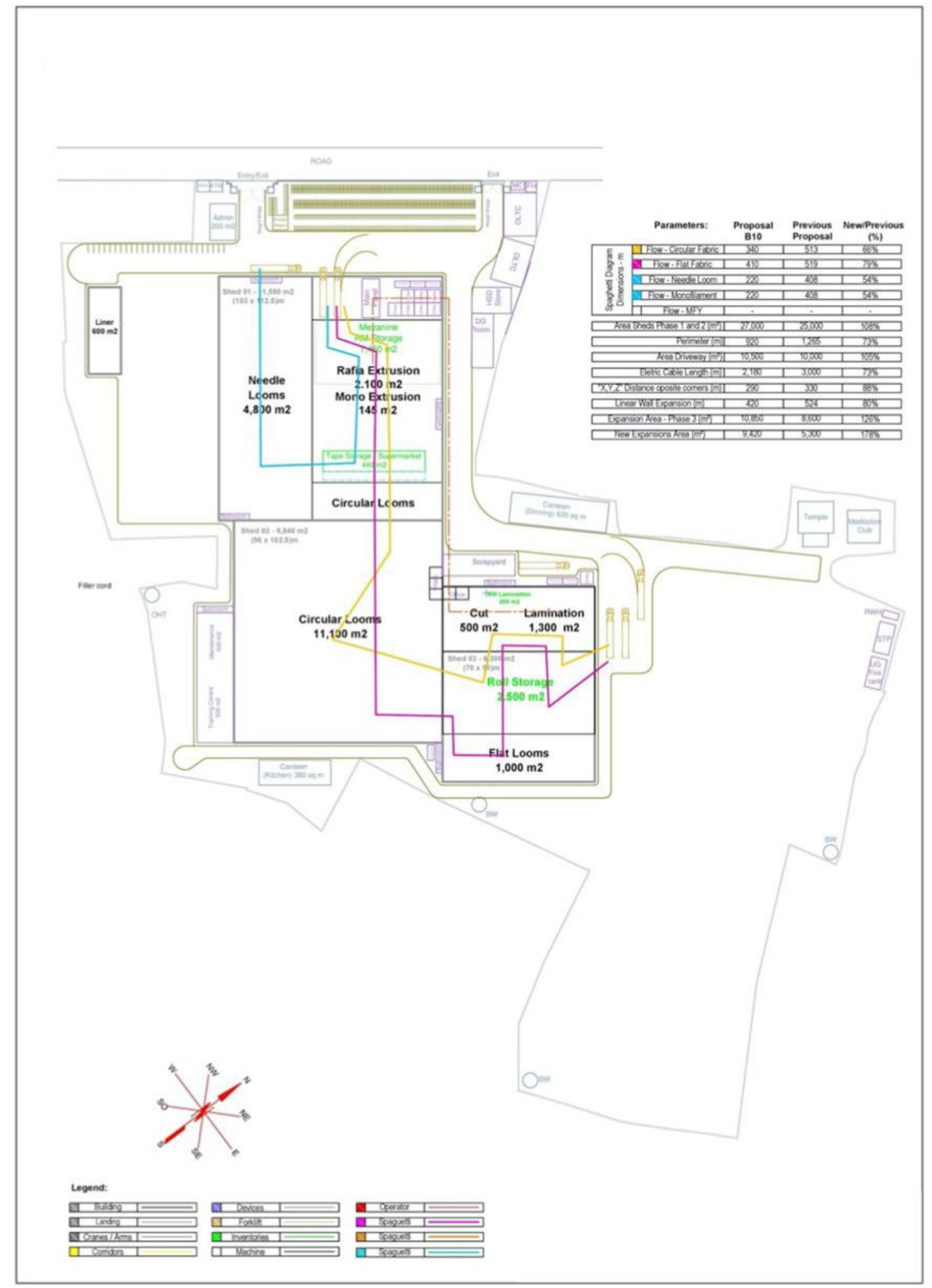

Figure 7. Macro Proposal B-10. 


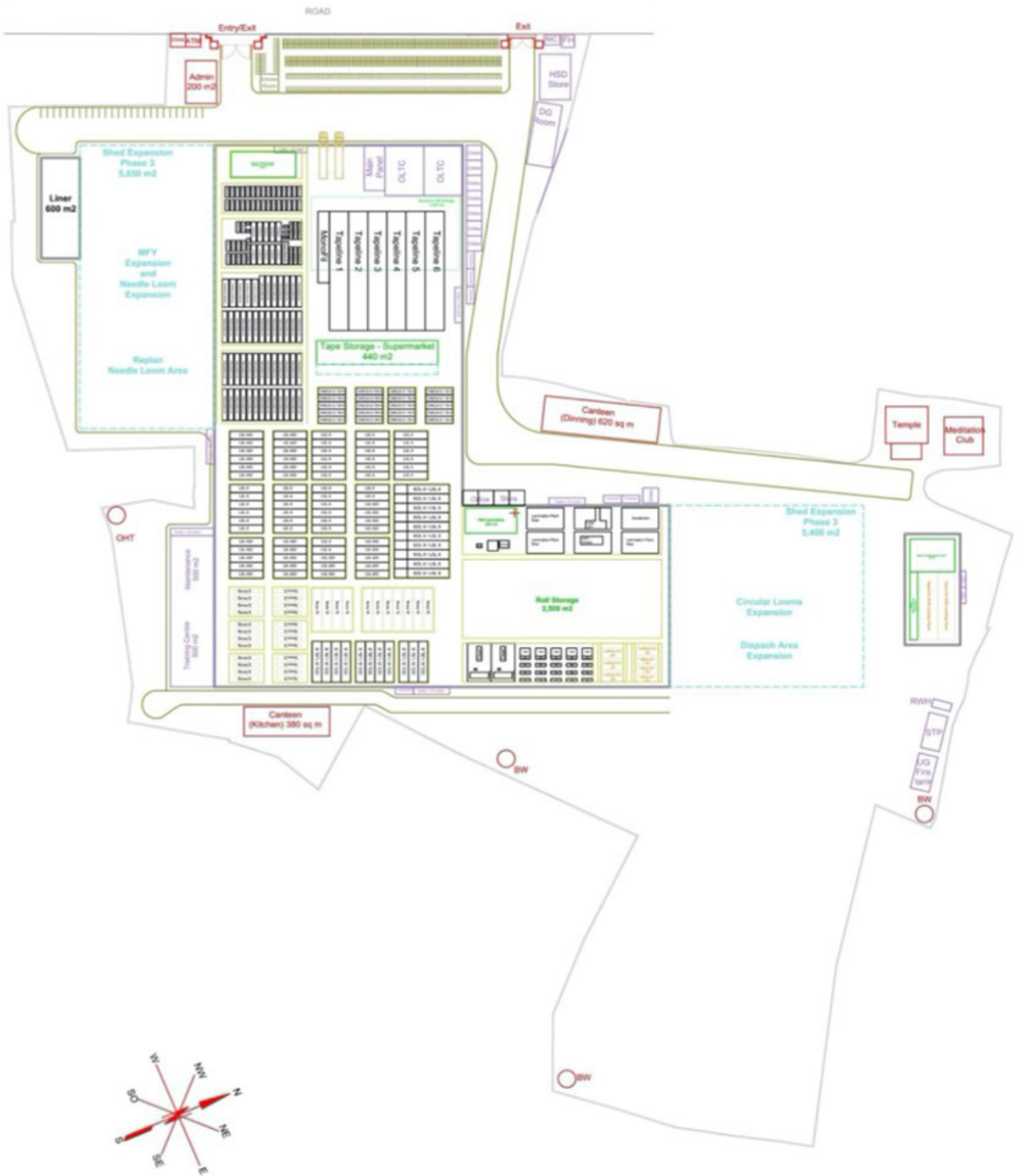

Legend:
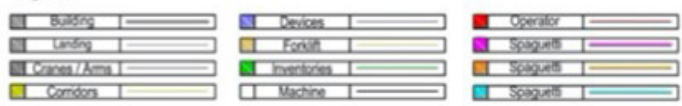

Figure 8. Macro Proposal B-11. 


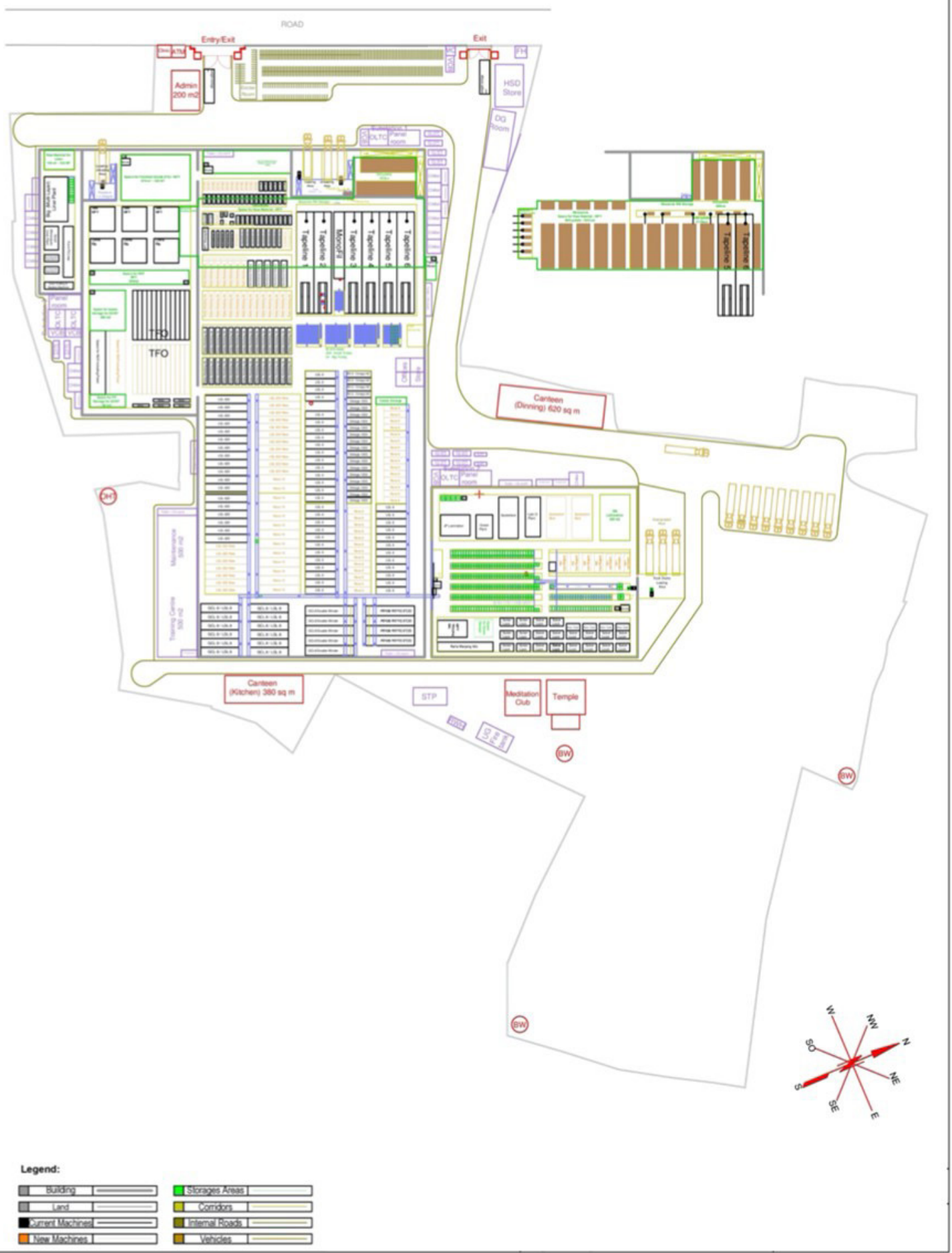

Figure 9. Final Micro Proposal. 
The last micro layout represents a set of processes, including roll storage, rolling, cutting, flat loom, and dispatch. The rolls coming from the circular loom are sent to stock. The laminating machines were allocated near the stock area to allow an interrupted supply of raw material, while the cutting machines are positioned close to roller racks and laminators.

Regarding the positioning of flat loom machines, these are allocated closer to the rolling stock since the demand for rollers is much larger and requires delicate transportation. The rolls accumulated in the stock goes to cutting and rolling and are later moved to the dispatch area. In addition, this proposal provided a space for loading materials and an external dispatch area, connected through a dock, where the forklifts can transport the finished products to the truck.

After designing a new layout for Industry ABC, it was possible to verify some considerable gains regarding the flow of materials for the main product families, as shown in Table 2. As it can be seen, significant reductions were obtained, especially for needle loom and monofilament flow (46\%) and circular fabric flow (34\%). Further, this new layout offers many social and economic benefits, since it derives from an overall redesign of the big bag manufacturing process. One of the most representative elements is the presence of cells, therefore, the operator of these activities can work in a smaller, more ergonomic area than before. This causes a significant reduction of the transportation of waste, which is a no-value added time. Furthermore, this new layout enables for easier transportation and materials flow, since resources and equipment are grouped to optimize the space used with greater control over production processes. For this layout, the workstations are organized sequentially according to the manufacturing process flow. The advantages of the previous layouts are proved here again.

Table 2. Comparison of Materials Flow Dimension based on Spaghetti Diagram.

\begin{tabular}{cccc}
\hline Product Family & Current Measure $(\mathrm{m})$ & Future Measure $(\mathrm{m})$ & Reduction $(\%)$ \\
\hline Circular Fabric Flow & 513 & 340 & 34 \\
Flat Fabric Flow & 519 & 410 & 21 \\
Needle Loom and Monofilament Flow & 408 & 220 & 46 \\
\hline
\end{tabular}

\section{Discussions}

Overall, the SLP model allowed the resolution of the plant distribution problem through the development of a sustainable layout proposal, which have provided several gains in social, economic and cultural terms. Regarding social contributions, it can be seen that the new layout improves the quality of work by reducing unnecessary movement and long routes. Before the application of the SLP technique, the company had a materials flow route of 1,440 meters per bag, while after the improvement it decreased to 970 meters. Needle loom and monofilament flow showed the highest reduction, demonstrating a considerable reduction in time caused by activities that do not generate value. In economic terms, the proposed layout allows efficient service provision and land utilization by optimizing the arrangement of materials flow in order to enhance the affordability of the development through reductions in the unit cost of land acquisition and service provision. Additionally, the layout design proves to be profitable since the income is expected to increase by $7 \%$ once the proposal is implemented.

Ideally, in layout planning, customers drive the decisions on the location of the facility and materials flow dictate part of the layout plan. However, an interesting finding of this case study based research was the relevance of religious traditions and domestic architecture in plant layout design. A "socio-cultural" consideration was not found explicitly mentioned in the literature review conducted on SLP methods. Yet, particularly when it comes to the stage of consideration of layout design constraints, it ended up having a significant relevance for this Indian case study due to their "Vastu" belief. More specifically, sheds shaping and the plots' balance were taken into consideration for creating layouts proposals. Such findings show that layout planning need to respond to the cultural context of a site by understanding traditional ways of making local cultural landscape. While religious traditions and domestic architecture may not be that relevant in western cultures when it comes to plants layouts design, it seems they are for many of the eastern cultures. Therefore, it is proposed their formal consideration in the stage of constraints considerations of SLP methods.

Summarizing, this paper offered a good basis to raise awareness about materials flow within the project team and led to a series of improvement measures that have been incorporated into the new plant layout design. Some difficulties are quantifying the effectiveness of these measures in a typical textile facility, mainly 
because the company is still adapting to the new processes and within the new layout structure. However, it is expected to improve the efficiency and quality of work significantly in the short term. Additionally, some results are expected with the implementation of the proposed plant layout: $(i)$ the optimized distribution of productive flows; (ii) prevention of organic growth of the shop floor are; (iii) oriented flows; (iv) shortest distance traveled in the material flow; $(v)$ reduced movement/transport of people and materials; $(v i)$ single warehouse allocating the entire manufacture chain; (vii) less number of movements for loading and unloading materials; (viii) better use of productive capacities; (ix) planned areas for allocating machinery; $(x)$ elimination of activities that do not add value; $(x i)$ shorter lead time; (xii) areas planned for future expansions; (xiii) reduction of costs with electrical cables used in extrusion; and (xiv) reduction in the wall-size construction.

\section{Conclusions}

The present work comprises the development of a plant layout based on LM principles and techniques for an Indian company that produces "Big Bags". The plant layout design was developed considering the flow of materials optimization and the religious premises of the Indian culture. Throughout its execution, proposals were created based on the application of layout development techniques (viz., VSM, activity relationship chart, block correlation area and spaghetti diagram). Such techniques facilitated the understanding of materials flow, and thus, contributed to the generation of improvement ideas.

Finally, it was possible to propose a macro layout design from the reorganization of the block areas within the facility. After finding a macro layout alternative that met the requirements of the project, the micro layout proposals were evaluated. This way, several individual micro layout proposals were designed for each group of families. The final step gathered the individual micro proposals into a single layout to incorporate all the best parts of each design. Results showed that the new SLP model allowed the resolution of the plant distribution problem through the development of a sustainable layout proposal, which have provided several gains. One of the most representative gains is the presence of cells, improving the quality of work. Our findings show a materials flow reduction of approximately $48 \%$, resulting in efficient service provision and land utilization by optimizing the arrangement of materials flow, besides minimizing unnecessary movement and long routes. Additionally, the layout design proves to be profitable since the income is expected to increase by $7 \%$ once the proposal is implemented.

Overall, the developed SLP model offered a good basis to raise awareness about wastes regarding material and process flows and led to a series of improvements measures that have been incorporated into the new plant layout and process design. This paper provides an original industrial case study with valuable insights for the adaptation of the SLP model to reformulate the plant design of a textile company. It is worthy to note that there were difficulties in implementing the method regarding the creation of layout alternatives. The existent practical limitations have generated an initial difficulty to expand the layout possibilities, due to dealing with cultural and structural changes. Moreover, the understanding of the demand variation was important to plan the production area. The results obtained are limited but could be very useful to the industry as they produced a set of guidelines for the redesign of a value stream map. The findings of this research are limited due to the focused nature of case study based research. However, the obtained results encourage assuming its transferability to similar problems. Further, in order to validate the proposed method in a broader context, the application of the SLP model should be extensively tested in different scenarios to compare results. Future studies could also verify the impact effectiveness of management actions in layout configuration in a long term. Moreover, since this research provides mainly a qualitative analysis, future research could be driven to develop mathematical models that explain the relationships among economic, cultural and social factors based on statistical procedures, such as structural equation modeling.

\section{References}

Bai, C., Satir, A., \& Sarkis, J. (2019). Investing in lean manufacturing practices: an environmental and operational perspective. International Journal of Production Research, 574), 1037-1051. http://dx.doi.org/10.1080/00207543.2018.1498986.

Brahmadeep, \& Thomassey, S. (2014). A simulation-based comparison: manual and automatic distribution setup in a textile yarn rewinding unit of a yarn dyeing factory. Simulation Modelling Practice and Theory, 45, 80-90. http://dx.doi.org/10.1016/j.simpat.2014.04.002.

De Carlo, F., Arleo, M. A., Borgia, O., and Tucci, M. (2013). Layout design for a low capacity manufacturing line: a case study. International Journal of Engineering Business Management, 5, 5-35. http://dx.doi.org/10.5772/56883.

Decker Junior, C., Ferreira, J. C. E., Henning, E., \& Pereira, C. R. (2019). Assessment of shop floor layouts in the context of process plans with alternatives. Production, 29, 29. http://dx.doi.org/10.1590/0103-6513.20180078. 
Djassemi, M. (2007). Improving factory layout under a mixed floor and overhead material handling condition. Journal of Manufacturing Technology Management, 18(3), 281-291. http://dx.doi.org/10.1108/17410380710730611.

Dongre, A., \& Mohite, N. Y. (2015). Significance of selection of material handling system design in industry - A review. International Journal of Engineering Research and General Science, 3(2), 76-79.

Durmusoglu, Z. D. (2018). A TOPSIS-based approach for sustainable layout design: activity relation chart evaluation. Kybernetes, 47(10), 2012-2024. http://dx.doi.org/10.1108/K-02-2018-0056.

Flessas, M., Rizzardi, V., Tortorella, G. L., Fettermann, D., \& Marodin, G. A. (2015). Layout performance indicators and systematic planning: A case study in a southern Brazilian restaurant. British Food Journal, 1178), 2098-2111. http://dx.doi.org/10.1108/BFJ-01-2015-0012.

Fogliatto, F. S., Tortorella, G. L., Anzanello, M. J., \& Tonetto, L. M. (2019). Lean-oriented layout design of a health care facility. Quality Management in Health Care, 28(1), 25-32. http://dx.doi.org/10.1097/QMH.0000000000000193. PMid:30586119.

Gnanavel, S. S., Balasubramanian, V., \& Narendran, T. T. (2015). Suzhal - An alternative layout to improve productivity and worker wellbeing in labor demanded lean environment. Procedia Manufacturing, 3, 574-580. http://dx.doi.org/10.1016/j.promfg.2015.07.268.

Henao, R., Sarache, W., \& Gómez, l. (2019). Lean manufacturing and sustainable performance: Trends and future challenges. Journal of Cleaner Production, 208, 99-116. http://dx.doi.org/10.1016/j.jclepro.2018.10.116.

Hicks, C., McGovern, T., Prior, G., \& Smith, 1. (2015). Applying lean principles to the design of healthcare facilities. International Journal of Production Economics, 170, 677-686. http://dx.doi.org/10.1016/j.jpe.2015.05.029.

Inglay, R. S., \& Dhalla, R. S. (2010). Application of systematic layout planning in hypermarkets. In Proceedings of the 2010 International Conference on Industrial Engineering and Operations Management (pp. 9-10). USA: IEOM Society International.

Jones, D., Womack, J., Brunt, D., Lovejoy, M., \& Shook, J. (2011). Seeing the whole value stream. Cambridge, USA: Lean Enterprise Institute.

Kim, T., Lim, H., Lee, U. K., Cha, M., Cho, H., \& Kang, K. 1. (2012). Advanced formwork method integrated with a layout planning model for tall building construction. Canadian Journal of Civil Engineering, 39(11), 1173-1183. http://dx.doi.org/10.1139/12012-104.

Klausnitzer, A., \& Lasch, R. (2019). Optimal facility layout and material handling network design. Computers \& Operations Research, 103, 237-251. http://dx.doi.org/10.1016/j.cor.2018.11.002.

Kovács, G. (2020). Combination of Lean value-oriented conception and facility layout design for even more significant efficiency improvement and cost reduction. International Journal of Production Research, 58(10), 1-21. http://dx.doi.org/10.1080/0020754 3.2020.1712490.

Lin, Q. L., Liu, H. C., Wang, D. J., \& Liu, L. (2015). Integrating systematic layout planning with fuzzy constraint theory to design and optimize the facility layout for operating theatre in hospitals. Journal of Intelligent Manufacturing, 26(1), 87-95. http://dx.doi. org/10.1007/s10845-013-0764-8.

Liu, J., \& Liu, J. (2019). Applying multi-objective ant colony optimization algorithm for solving the unequal area facility layout problems. Applied Soft Computing, 74, 167-189. http://dx.doi.org/10.1016/j.asoc.2018.10.012.

Luz, G. P., Tortorella, G. L., Bouzon, M., Garza-Reyes, J., \& Gaiardelli, P. (2020). Proposition of a method for stochastic analysis of value streams. Production Planning and Control, 1-17. http://dx.doi.org/10.1080/09537287.2020.1833377.

Marodin, G. A., Saurin, T. A., Tortorella, G. L., \& Denicol, J. (2015). How context factors influence lean production practices in manufacturing cells. International Journal of Advanced Manufacturing Technology, 79(5), 1389-1399. http://dx.doi.org/10.1007/ s00170-015-6944-2.

Matt, D. T. (2014). Adaptation of the value stream mapping approach to the design of lean engineer-to-order production systems. Journal of Manufacturing Technology Management, 25(3), 334-350. http://dx.doi.org/10.1108/JMTM-05-2012-0054.

Muther, R. (1973). Systematic layout planning. Kansas City: Management \& Industrial Research Publication.

Naqvi, S. A., Fahad, M., Atir, M., Zubair, M., \& Shehzad, M. M. (2016). Productivity improvement of a manufacturing facility using systematic layout planning. Cogent Engineering, 3(1), 1207296. http://dx.doi.org/10.1080/23311916.2016.1207296.

Pattanaik, L. N., \& Sharma, B. P. (2009). Implementing lean manufacturing with cellular layout: a case study. International Journal of Advanced Manufacturing Technology, 42(7-8), 772-779. http://dx.doi.org/10.1007/s00170-008-1629-8.

Rawabdeh, 1., \& Tahboub, K. (2006). A new heuristic approach for a computer-aided facility layout. Journal of Manufacturing Technology Management, 17(7), 962-986. http://dx.doi.org/10.1108/17410380610688269.

Rother, M., \& Shook, J. (2003). Learning to see: value stream mapping to add value and eliminate muda. Cambridge, USA: Lean Enterprise Institute.

Ruiz, S., Simón, A., Sotelo, F., \& Raymundo, C. (2019). Optimized plant distribution and 5S model that allows SMEs to increase productivity in textiles. In: Proceedings of the LACCEI International Multi-Conference for Engineering, Education and Technology. Montego Bay, Jamaica. http://dx.doi.org/10.18687/LACCEl2019.1.1.59.

Santos, L. C., Cláudia Fabiana, G. O. H. R., \& Urio, L. C. S. (2014). Planejamento sistemático de layout em pequenas empresas: uma aplicação em uma fábrica de baterias automotivas. Revista Espacios, 35(7), 14.

Santos, Y. M., Torres, O. V. C., Leyva, L. L. L., Granda, I. D. H., Orges, C. A. M., \& Saraguro Piarpuezan, R. V. (2019, July 23-26). Improvement plant layout of production line in textile company: a case study. In Proceedings of the International Conference on Industrial Engineering and Operations Management (pp. 741-750). Pilsen, Czech Republic.

Shewale, P. P., Shete, M. S., \& Sane, S. M. (2012). Improvement in plant layout using systematic layout planning (SLP) for increased productivity. International Journal of Advanced Engineering Research and Studies, 1(3), 259-261.

Slack, N., Chambers, S., \& Johnston, R. (2010). Operations management (6th ed.). Hoboken: Financial Times Prentice Hall.

Tomelin, M., \& Colmenero, J. C. (2010). Método para definição de layout em sistemas job-shop baseado em dados históricos. Production, 20(2), 274-289. http://dx.doi.org/10.1590/S0103-65132010005000026.

Tortorella, G. L., \& Fogliatto, F. S. (2008). Planejamento sistemático de layout com apoio de análise de decisão multicritério. Production, 18(3), 609-624. http://dx.doi.org/10.1590/S0103-65132008000300015. 
Tortorella, G. L., Fogliatto, F. S., Anzanello, M., Marodin, G. A., Garcia, M., \& Reis Esteves, R. (2017). Making the value flow: application of value stream mapping in a Brazilian public healthcare organisation. Total Quality Management \& Business Excellence, 28(13-14), 1544-1558. http://dx.doi.org/10.1080/14783363.2016.1150778.

Tortorella, G., Silva, G., Campos, L. M. S., Pizzeta, C., Latosinski, A., \& Soares, A. (2018). Productivity improvement in solid waste recycling centres through lean implementation aided by multi-criteria decision analysis. Benchmarking, 25(5), 1480-1499. http:// dx.doi.org/10.1108/BlJ-01-2017-0013.

Watanapa, A., and Wiyaratn, W. (2012). Systematic layout planning to assist plant layout: case study pulley factory. Applied Mechanics and Materials, 110-116, 3952-3956.

Yang, T., Su, C. T., \& Hsu, Y. R. (2000). Systematic layout planning: a study on semiconductor wafer fabrication facilities. International Journal of Operations \& Production Management, 20(11), 1359-1371. http://dx.doi.org/10.1108/01443570010348299.

Zhang, Z., Wang, X., Wang, X., Cui, F., \& Cheng, H. (2019). A simulation-based approach for plant layout design and production planning. Journal of Ambient Intelligence and Humanized Computing, 10(3), 1217-1230. http://dx.doi.org/10.1007/s12652-018-0687-5.

Zhenyuan, J., Xiaohong, L. U., Wei, W., Defeng, J., \& Lijun, W. (2011). Design and implementation of lean facility layout system of a production line. International Journal of Industrial Engineering, 18(5), 260-269. 